\title{
Effects of Nitric Oxide Fumigation on Mortality of Light Brown Apple Moth, Epiphyas postvittana (Lepidoptera: Tortricidae)*
}

\author{
Yong-Biao Liu* (ㄷ, Gregory S. Simmons \\ USDA-ARS, Salinas, CA, USA \\ Email: *yongbiao.liu@usda.gov
}

How to cite this paper: Liu, Y.-B. and Simmons, G.S. (2021) Effects of Nitric Oxide Fumigation on Mortality of Light Brown Apple Moth, Epiphyas postvittana (Lepidoptera: Tortricidae). Agricultural Sciences, 12, 1286-1294.

https://doi.org/10.4236/as.2021.1211082

Received: September 9, 2021

Accepted: November 14, 2021

Published: November 17, 2021

Copyright $\odot 2021$ by author(s) and Scientific Research Publishing Inc. This work is licensed under the Creative Commons Attribution International License (CC BY 4.0).

http://creativecommons.org/licenses/by/4.0/

\begin{abstract}
Light brown apple moth, Epiphyas postvittana, is a quarantine pest in most countries and has established in California and, therefore, has potential to affect export of fresh products from infested areas. There is currently lack of effective treatment especially against eggs. Nitric oxide is a recently discovered fumigant for postharvest pest control and is evaluated in laboratory fumigations to determine its efficacy against different life stages of this pest. Small scale fumigations with nitric oxide at $1.0 \%, 2.0 \%, 3.0 \%$, and $5.0 \%$ concentrations were conducted under ultralow oxygen conditions at $2^{\circ} \mathrm{C}$ against larvae, pupae, and eggs of light brown apple moth. Treatment times ranged from 4 to $24 \mathrm{~h}$ depending on nitric oxide concentration and life stage. Complete control of larvae and pupae was achieved in $8 \mathrm{~h}$ fumigation with $2.0 \%$ NO. Eggs were successfully controlled in 6,12 , and $24 \mathrm{~h}$ fumigations with $5.0 \%, 3.0 \%$, and $2.0 \% \mathrm{NO}$ respectively. The study demonstrated that nitric oxide fumigation was effective against all life stages of light brown apple moth and, therefore, has potential to be an alternative treatment to methyl bromide fumigation for postharvest control of light brown apple moth.
\end{abstract}

\section{Keywords}

Quarantine Treatment, Nitric Oxide, Fumigation, Light Brown Apple Moth

\section{Introduction}

Light brown apple moth (LBAM), Epiphyas postvittana (Lepidoptera: Tortrici-

*This article reports the results of research only. Mention of proprietary products, trade names or commercial products in this publication is not for the purpose of providing specific information and does not constitute an endorsement or a recommendation by the U.S. Department of Agriculture for its use. The USDA is an equal opportunity provider and employer. 
dae), has established in California since its early detection over 10 years ago and could spread to other regions. This pest has a very broad host range of over 500 plant species in $>100$ families [1] [2] [3]. LBAM has been reported to cause significant losses of crop production [4] [5]. Although LBAM infestations in California mainly occur on nursery plants, it has potential to be a pest on many other crops. LBAM has a very limited distribution and is a quarantine pest in most countries. Fresh products from infested areas, therefore, face both domestic and international quarantine [1] [6]. A postharvest treatment for LBAM control is needed to meet the need of a quarantine treatment for LBAM control on affected fresh commodities.

The current treatment with methyl bromide fumigation is unsustainable due to the global phase out of methyl bromide production and uncertainty of the critical use exception for methyl bromide in the future. Currently, phosphine and sulfuryl fluoride are two major alternative fumigants for postharvest pest control. However, phosphine fumigation typically has long treatment time and treatments of over 10 days may be required to control some stored product insects [7] [8]. Some insects especially at egg or pupa stages have high tolerance to phosphine fumigation and some insects have developed resistance to phosphine [9] [10]. Sulfuryl fluoride fumigation is not effective in controlling insect eggs and is phytotoxic to fresh products [11] [12]. In recent years, ethyl formate fumigation has been tested and used on selective fresh products for postharvest control of some specific pests. But it may have limited applications on fresh products due to its phytotoxicity to most fresh products [13]. Therefore, new alternatives are needed for postharvest control of many pests including LBAM on international traded fresh products. Nitric oxide was recently discovered to be a potent fumigant against a wide variety of insect pests at various life stages and mites [14] [15] but no detailed toxicity data on LBAM has been reported.

Nitric oxide is a ubiquitous cell signal molecule in most organisms including microbes, plants, and animals. It is also produced naturally in fossil fuel combustion and lightning, and manufactured for fertilizer production. It is used in medical fields to treat certain respiratory and cardio vascular conditions [16] [17]. It is also being studied for enhancing postharvest quality and prolonging shelf-life of fresh fruits [18] [19].

Nitric oxide reacts spontaneously with oxygen to produce nitrogen dioxide $\left(\mathrm{NO}_{2}\right)$ [20]. Therefore, NO fumigation must be conducted under ultralow oxygen (ULO) conditions to preserve NO. As a fumigant, nitric oxide can kill insects in as short as $2 \mathrm{~h}$ at a high concentration of $2 \%-5 \%$ [14]. The efficacy increases with concentration, treatment time, and temperature. There are also variations in susceptibility among different insect species and life stages [14]. Eggs are more tolerant of NO fumigation than mobile stages. Small soft body insects such as aphid and thrips are very easy to control and can be controlled in $2-3 \mathrm{~h}$ at low temperatures. Stored product insects such as weevils and beetles are more tolerant but can still be controlled in $72 \mathrm{~h}$ with $2 \%-3 \% \mathrm{NO}$ fumigation 
[14]. In addition to pest control, NO fumigation can also have desired levels of $\mathrm{NO}_{2}$ for microbial control by controlling oxygen level before $\mathrm{NO}$ injection and $\mathrm{NO}_{2}$ has been demonstrated to be effective in controlling Aspergillus flavus spores on artificial medium and bacteria and fungi on stored almonds and peanuts [15] [21] [22] [23].

Nitric oxide fumigation for fresh products also needs to be terminated by flushing the fumigation chamber with nitrogen to dilute NO before exposing products to ambient air to prevent reaction of $\mathrm{NO}$ with $\mathrm{O}_{2}$ to produce $\mathrm{NO}_{2}$. The production of $\mathrm{NO}_{2}$ may cause injuries to fresh products [24]. When terminated properly with $\mathrm{N}_{2}$ flush, $\mathrm{NO}$ fumigation was demonstrated to be safe to postharvest quality of fresh products and even improve postharvest quality as demonstrated on strawberries [24]. In this study, LBAM eggs, larvae, and pupae were fumigated with $\mathrm{NO}$ to determine an effective treatment against all of the life stages.

\section{Materials and Methods}

\subsection{Insects}

E. postvittana was collected from Santa Cruz County in California in 2007 and reared on artificial pink bollworm diet at the U.S. Department of Agriculture-Animal and Plant Health Inspection Services-Plant Protection and Quarantine-Center for Plant Health Science and Technology (USDA-APHIS-PPQ-CPHST) laboratory in Salinas, California. Moths were held in cages and fed with $10 \%$ sucrose solution supplied in saturated cotton rods. Corrugated wax papers were lined along the walls of the cages as substrates to collect eggs. Egg sheets were collected within $24 \mathrm{~h}$ and used for fumigation experiments immediately. They were cut into pieces and each piece contained 100 - 200 eggs based on visual estimation. Each piece of egg sheet was placed in a plastic vial $(3 \mathrm{~cm}$ diam. $\times 7 \mathrm{~cm}$ high). A piece of yellow sticky card was also suspended in each vial to catch neonates after they hatched from surviving eggs.

\subsection{Chemicals}

Nitric oxide ( $>99.5 \%$ purity) in a compressed cylinder was obtained from a commercial source. It was then released and stored in a foil bag to be used in fumigations tests. Commercial grade nitrogen gas in compressed cylinders from a commercial source was used.

\subsection{Effects of Nitric Oxide Fumigation Treatments on Mortality of Eggs}

As it is known that insect eggs are more tolerant to NO fumigation than other life stages based on the earlier study [14], LBAM eggs were fumigated first to determine effective treatments than larvae and pupae. LBAM eggs were fumigated with $1.0 \%, 2.0 \%, 3.0 \%$, and $5.0 \% \mathrm{NO}$ in $1.9 \mathrm{~L}$ jars for 6,12 , and $24 \mathrm{~h}$ to determine effective treatments. Egg sheets with $<48 \mathrm{~h}$ old eggs were cut into pieces 
each containing 100 - 200 eggs based on visual estimation and placed individually in plastic vials ( $3 \mathrm{~cm}$ diam. $\times 7 \mathrm{~cm}$ high). A piece of yellow sticky card was also suspended in each vial to catch neonates hatched from surviving eggs. In each fumigation test, four vials with eggs in each jar were fumigated with each NO concentration for one treatment time and unfumigated eggs were also included as controls. The fumigation test for each treatment time was replicated four times.

After fumigation, vials with LBAM eggs were incubated in an environmental chamber for over two weeks to allow all viable eggs to hatch and neonates trapped on sticky cards. The sticky cards were then inspected to count all trapped neonates to estimate egg mortality. We assumed that each vial had the same number of eggs and treatment mortality was calculated based on neonates for each treatment and neonates for the controls.

\subsection{Effects of Nitric Oxide Fumigation Treatments on Mortality of Larvae and Pupae}

LBAM larvae and pupae were fumigated with $2.0 \% \mathrm{NO}$ in $1.9 \mathrm{~L}$ jars under ULO condition of $\leq 30 \mathrm{ppm} \mathrm{O}_{2}$ at $2^{\circ} \mathrm{C}$ for $4,6,8$, and $12 \mathrm{~h}$ to determine their susceptibility to NO fumigation. The $2.0 \% \mathrm{NO}$ was selected based on its effects on LBAM eggs in the above experiment. Larvae of medium to large sizes were collected from rearing media in a group of 10 in small screened cages with small amount of diet. Pupae were collected and confined in a group of 10 in screened cages without diet. In each fumigation test, five vials with larvae and five vials with pupae were placed in each jar for each treatment time. Each treatment time was replicated 5 - 10 times. After fumigation, larvae and pupae were incubated in an environmental chamber overnight before being evaluated for mortality. Larvae and pupae that were unresponsive to probes with a pin were classified as dead.

\subsection{Data Analysis}

Mortalities for each treatment time and each life stage were transformed by arcsine $\sqrt{x}$ before being subjected to one-way ANOVA and Tukey HSD multiple range test to compare mortalities among different NO concentrations. The fit model platform of JMP statistical discovery software was used for all statistical analyses [25].

\section{Results and Discussion}

Nitric oxide fumigation was effective against larvae, pupae, and eggs of LBAM. Complete control of eggs was achieved in the $6 \mathrm{~h}$ with $5.0 \% \mathrm{NO}, 12 \mathrm{~h}$ with $3.0 \%$ $\mathrm{NO}$, and $24 \mathrm{~h}$ with $2.0 \% \mathrm{NO}$ treatments at $2^{\circ} \mathrm{C}$ (Table 1). Larvae and pupae were more susceptible to NO fumigation than eggs and complete control of larvae and pupae was achieved in the $8 \mathrm{~h}$ fumigation with $2.0 \% \mathrm{NO}$ at the same low temperature (Table 2). In the $6 \mathrm{~h}$ fumigations, $2.0 \% \mathrm{NO}$ treatment had $26.7 \%$ egg 
Table 1. Effects of nitric oxide fumigations with different combinations of dose and treatment time on mortality of light brown apple moth eggs.

\begin{tabular}{|c|c|c|c|c|}
\hline Time (h) & NO (\%) & Total & $\begin{array}{c}\text { Mortality (\%) } \\
(\text { Mean } \pm \text { SE) }\end{array}$ & ANOVA \\
\hline \multirow[t]{4}{*}{6} & 1.0 & 1808 & $20.07 \pm 2.43 b$ & $\mathrm{Df}=5,114$ \\
\hline & 2.0 & 1527 & $26.70 \pm 3.76 b$ & $\mathrm{~F}=153.58$ \\
\hline & 3.0 & 1938 & $93.87 \pm 3.62 \mathrm{a}$ & $\mathrm{P}<0.0001$ \\
\hline & 5.0 & 2000 & $100 \mathrm{a}$ & \\
\hline \multicolumn{2}{|c|}{ C-ULO } & 1690 & $19.74 \pm 3.61 b$ & \\
\hline \multicolumn{2}{|c|}{ Control } & 1820 & $21.35 \pm 3.38 b$ & \\
\hline \multirow[t]{4}{*}{12} & 1.0 & 1255 & $62.79 \pm 8.49 b$ & $\mathrm{Df}=5,90$ \\
\hline & 2.0 & 1567 & $99.94 \pm 0.06 a$ & $F=100.13$ \\
\hline & 3.0 & 1571 & $100 \mathrm{a}$ & $\mathrm{F}<0.0001$ \\
\hline & 5.0 & 1566 & $100 \mathrm{a}$ & \\
\hline \multicolumn{2}{|c|}{ C-ULO } & 1174 & $18.55 \pm 4.20 c$ & \\
\hline \multicolumn{2}{|c|}{ Control } & 1141 & $16.60 \pm 3.35 c$ & \\
\hline \multirow[t]{4}{*}{24} & 1.0 & 1181 & $54.38 \pm 6.60 b$ & $\mathrm{Df}=5,84$ \\
\hline & 2.0 & 1511 & $100 \mathrm{a}$ & $F=189.90$ \\
\hline & 3.0 & 1520 & $100 \mathrm{a}$ & $\mathrm{P}<0.0001$ \\
\hline & 5.0 & 1496 & $100 \mathrm{a}$ & \\
\hline \multicolumn{2}{|c|}{ C-ULO } & 1187 & $14.83 \pm 2.95 c$ & \\
\hline \multicolumn{2}{|c|}{ Control } & 1197 & $13.20 \pm 3.39 c$ & \\
\hline
\end{tabular}

Mortality data were transformed by $\operatorname{arcsine} \sqrt{x}$ prior to statistical analysis. For each treatment time, mortalities followed by the same letter were not significantly different at P $>0.05$ based on Tukey HSD multiple range test using JMP Statistical Discover Software (SAS Institute 2012).

mortality. In comparison, the same treatment resulted in $>99 \%$ mortality of larvae and pupae (Table 1 and Table 2). There were no significant differences in mortality between the two types of controls, normal atmosphere and ULO atmosphere (Table 1 and Table 2).

The responses of different life stages of LBAM to NO fumigation are consistent with responses of other insects with mobile life stages more susceptible and eggs most tolerant [14]. Susceptibility of LBAM to NO fumigation is higher as compared with stored product insects and internal feeding insects such as codling moth larvae [14] [26].

It is challenging to find an effective alternative fumigant to control LBAM especially eggs. Cylindered pure phosphine has been used for postharvest pest control on fresh products in recent years [27] [28] [29]. It was also studied for control of LBAM on fresh products. Phosphine fumigation is not very effective 
Table 2. Effects of nitric oxide fumigation on mortality of light brown apple moth larvae and pupae.

\begin{tabular}{|c|c|c|c|c|c|}
\hline \multirow[b]{2}{*}{ NO (\%) } & \multirow[b]{2}{*}{ Time (h) } & \multicolumn{2}{|r|}{ Larvae } & \multicolumn{2}{|r|}{ Pupae } \\
\hline & & Total & $\begin{array}{c}\text { Mortality (\%) } \\
(\text { Mean } \pm \text { SE) }\end{array}$ & Total & Mortality $(\%)($ Mean \pm SE) \\
\hline \multirow{4}{*}{2.0} & 4 & 300 & $92.68 \pm 1.79 b$ & 290 & $91.00 \pm 2.11 b$ \\
\hline & 6 & 400 & $99.75 \pm 0.25 \mathrm{a}$ & 398 & $99.75 \pm 0.25 a$ \\
\hline & 8 & 501 & $100 \mathrm{a}$ & 498 & $100 \mathrm{a}$ \\
\hline & 12 & 250 & $100 \mathrm{a}$ & 251 & $100 \mathrm{a}$ \\
\hline \multicolumn{2}{|c|}{ C-ULO } & 652 & $4.87 \pm 1.15 c$ & 638 & $13.15 \pm 2.25 c$ \\
\hline \multicolumn{2}{|c|}{ Control } & 646 & $2.18 \pm 0.99 c$ & 615 & $9.60 \pm 1.79 c$ \\
\hline \multirow{3}{*}{\multicolumn{2}{|c|}{ ANOVA }} & \multicolumn{2}{|c|}{$\mathrm{Df}=5,219$} & \multicolumn{2}{|r|}{$\mathrm{Df}=5,219$} \\
\hline & & \multicolumn{2}{|c|}{$\mathrm{F}=1289.244$} & \multicolumn{2}{|r|}{$F=593.372$} \\
\hline & & \multicolumn{2}{|c|}{$\mathrm{P}<0.0001$} & \multicolumn{2}{|r|}{$\mathrm{P}<0.0001$} \\
\hline
\end{tabular}

Mortality data were transformed by $\operatorname{arcsine} \sqrt{x}$ prior to statistical analysis. For each treatment time, mortalities followed by the same letter were not significantly different at $\mathrm{P}>0.05$ based on Tukey HSD multiple range test using JMP Statistical Discover Software (SAS Institute 2012).

against LBAM eggs. Oxygenated phosphine fumigation (fumigation under high oxygen conditions) is more effective than regular phosphine fumigation but still takes $72 \mathrm{~h}$ fumigation with high phosphine concentrations to have a complete control of LBAM eggs [30] [31]. The effective control of LBAM larvae, pupae, and eggs suggests that NO fumigation has better efficacy than phosphine fumigation to control LBAM. Therefore, NO fumigation as demonstrated in this study is the only fumigation treatment that is effective against LBAM eggs.

In an earlier study, ten fresh fruit and vegetables were subjected to $4 \mathrm{~h}$ fumigations with $1.0 \% \mathrm{NO}$ at $2^{\circ} \mathrm{C}$. NO fumigations that were terminated by $\mathrm{N}_{2}$ flush to prevent $\mathrm{NO}$ reaction with $\mathrm{O}_{2}$ to form $\mathrm{NO}_{2}$ were safe to all of ten fresh fruit and vegetables [24]. Iceberg lettuce was also fumigated with $0.5 \% \mathrm{NO}$ for $16 \mathrm{~h}$ to control lettuce aphid and the treatment was safe to lettuce quality [32]. Strawberries were also fumigated with $3.0 \% \mathrm{NO}$ for $16 \mathrm{~h}$ for control of spotted wing drosophila and the treatment had no negative impact on strawberry quality [33]. In the current study, the 6 and $12 \mathrm{~h}$ fumigations with 5\% and 3\% NO that had complete control of LBAM eggs had a lower CxT product than the $16 \mathrm{~h}$ and 3.0\% NO fumigation for strawberries [33]. Therefore, the treatments for LBAM eggs are expected to be safe to those previously tested fresh products. LBAM has very broad host range and past infestations mainly occurred on nursery plants [2] [3]. In the past NO fumigation studies, harvested fresh products that had been subjected to cold storage were subjected to NO fumigations [24] [27] [32] [33]. During NO fumigation, there is no oxygen and fresh products are subjected to extreme hypoxia stress. Harvested fresh products that have been subjected to 
cold storage have slower metabolism and less requirement for oxygen [34] [35]. Therefore, they are expected to be more tolerant to NO fumigation as compared with live plants with active metabolism. For dormant nursery products such as flower bulbs, NO fumigation that is capable to control LBAM has been demonstrated to be safe in an earlier study [36]. However, it is unknow whether NO fumigation is safe to live nursery plants especially those valued for cosmetic appearances and more research is warranted.

\section{Acknowledgements}

We would like to thank T. Greene, T. Masuda, and J. Wasson for technical assistance. This research was supported in part by TASC grant (C2017-04) from USDA Foreign Agricultural Service.

\section{Conflicts of Interest}

The authors declare no conflicts of interest regarding the publication of this paper.

\section{References}

[1] Johnson, M.W., Pickel, C., Strand, L.L., Varela, L.G., Wilen, C.A., Bolda, M.P., Flint, M.L., Lam, W.K.F. and Zalom, F.G. (2007) Light Brown Apple Moth in California: Quarantine, Management, and Potential Impacts. University of California Agriculture and Natural Resources, UC Statewide Integrated Pest Management Program.

[2] Suckling, D.M. and Brockerhoff, E.G. (2010) Invasion Biology, Ecology, and Management of the Light Brown Apple Moth (Tortricidae). Annual Review of Entomology, 55, 285-306. https://doi.org/10.1146/annurev-ento-112408-085311

[3] Brockerhoff, E.G., Suckling, D.M., Ecroyd, C.E., Wagstaff, S.J., Raabe, M.C., Dowell, R.V. and Wearing, C.H. (2011) Worldwide Host Plants of the Highly Polyphagous, Invasive Epiphyas postvittana (Lepidoptera: Tortricidae). Journal of Economic Entomology, 104, 1514-1524. https://doi.org/10.1603/EC11160

[4] Danthanarayana, W. (1975) The Bionomics, Distribution and Host Range of the Light Brown Apple Moth, Epiphyas postvittana (Walk.) (Tortricidae). Australian Journal of Zoology, 23, 419-437. https://doi.org/10.1071/ZO9750419

[5] USDA-APHIS (2010) APHIS Draft Response to Petitions for the Reclassification of Light Brown Apple Moth [Epiphyas postvittana (Walker)] as a Non-Quarantine Pest, v2. Plant Epidemiology and Risk Analysis Laboratory, Center for Plant Health Science and Technology, Plant Protection and Quarantine, USDA-APHIS. https://www.panna.org/sites/default/files/imported/files/draft lbam petition respo nse-10.pdf

[6] CDFA (California Department of Food and Agriculture) (2013) California Department of Food and Agriculture Plant Quarantine Manual: 3434. Light Brown Apple Moth. http://pi.cdfa.ca.gov/pqm/manual/pdf/419.pdf

[7] Howe, R.W. (1974) Problems in the Laboratory Investigation of the Toxicity of Phosphine to Stored Product Insects. Journal of Stored Product Research, 10, 167-181. https://doi.org/10.1016/0022-474X(74)90005-8

[8] Hole, B.D., Bell, C.H., Mills, K.A. and Goodship, G. (1976) The Toxicity of Phosphine to All Developmental Stages of Thirteen Species of Stored Product Beetles. 
Journal of Stored Product Research, 12, 235-244. https://doi.org/10.1016/0022-474X(76)90039-4

[9] Collins, P.J. (1998) Resistance to Grain Protectants and Fumigants in Insect Pests of Stored Products in Australia. Proceedings of the 1st Australian Postharvest Technical Conference, Canberra, May 1998, 55-57.

[10] Nayak, M.K., Collins, P.J. and Pavic, H. (2007) Develop Fumigation Protocols to Manage Strongly Phosphine-Resistant Rice Weevils, Sitophilus oryzae (L.). Proceedings of the International Conference Controlled Atmosphere and Fumigation in Stored Products, Gold Coast, 8-13 August 2004, 267-273.

[11] Bell, C.H., Savvidou, N. and Wontner Smith, T.J. (1999) The Toxicity of Sulfuryl Fluoride (Vikane) to Eggs of Insect Pests of Flour Mills. Proceedings of the 7 th International Working Conference on Stored-Product Protection, Beijing, 14-19 October 1998, 345-350.

[12] Aung, L.H., Leesch, J.G., Jenner, J.F. and Grafton-Cardwell, E.E. (2001) Effects of Carbonyl Sulfide, Methyl Iodide, and Sulfuryl Fluoride on Fruit Phytotoxicity and Insect Mortality. Annals of Applied Biology, 139, 93-100.

https://doi.org/10.1111/j.1744-7348.2001.tb00133.x

[13] Zoffolia, J.P., Michelow, P. and Naranjo, P. (2013) Sensitivity of Fruit Species to Ethyl Formate Fumigation under Quarantine Concentrations. In: Abdullah, H. and Latifah, M.N., Eds., ISHS Acta Horticulturae 1012: VII International Postharvest Symposium, ISHS, Kuala Lumpur, 763-767. https://doi.org/10.1111/j.1744-7348.2001.tb00133.x

[14] Liu, Y.B. (2013) Nitric Oxide as a Potent Fumigant for Postharvest Pest Control. Journal of Economic Entomology, 106, 2267-2274. https://doi.org/10.1603/EC13249

[15] Liu, Y.B., Oh, S. and Yang, X. (2021) Nitric Oxide Fumigation for Postharvest Control of Pests and Pathogens. Proceedings of the 11 th International Conference on Controlled Atmosphere and Fumigation in Stored Products (CAF2020), Winnipeg, 22-27 August 2021, 288-295.

[16] Roberts, J.D., Lang, P., Bigatello, L.M., Vlahakes, G.J. and Zapol, W.M. (1993) Inhaled Nitric Oxide in Congenital Heart Disease. Circulation, 87, 447-453.

https://doi.org/10.1161/01.CIR.87.2.447

[17] Ricciardolo, F.L.M., Sterk, P.J., Gaston, B. and Folkerts, G. (2004) Nitric Oxide in Health and Disease of the Respiratory System. Physiological Reviews, 84, 731-765. https://doi.org/10.1152/physrev.00034.2003

[18] Soegiarto, L. and Wills, R.B.H. (2004) Short Term Fumigation with Nitric Oxide Gas in Air to Extend the Postharvest Life of Broccoli, Green Bean, and Bok Choy. HortTechnology, 14, 538-540. https://doi.org/10.21273/HORTTECH.14.4.0538

[19] Manjunatha, G., Lokesh, V. and Neelwarne, B. (2010) Nitric Oxide in Fruit Ripening: Trends and Opportunities. Biotechnology Advances, 28, 489-499. https://doi.org/10.1016/j.biotechadv.2010.03.001

[20] Beckman, J.S. and Koppenol, W.H. (1996) Nitric Oxide, Superoxide, and Peroxynitrite: The Good, the Bad, and the Ugly. American Journal of Physiology: Cell Physiology, 271, C1424-C1437. https://doi.org/10.1152/ajpcell.1996.271.5.C1424

[21] Liu, Y.B., Oh, S. and Jurick, W.M. (2019) Response of Aspergillus flavus Spores to Nitric Oxide Fumigations in Atmospheres with Different Oxygen Concentrations. Journal of Stored Product Research, 83, 78-83. https://doi.org/10.1016/j.jspr.2019.06.001

[22] Oh, S. and Liu, Y.B. (2020) Effectiveness of Nitrogen Dioxide Fumigation for Mi- 
crobial Control on Stored Almonds. Journal of Food Protection, 83, 599-604. https://doi.org/10.4315/0362-028X.JFP-19-281

[23] Oh, S., Singh, R. and Liu, Y. (2020) Nitrogen Dioxide Fumigation for Microbial Control on Unshelled Peanuts. Agricultural Sciences, 11, 1159-1169. https://doi.org/10.4236/as.2020.1112076

[24] Liu, Y.B. (2016) Nitric Oxide Fumigation for Control of Western Flower Thrips and Its Safety to Postharvest Quality of Fresh Fruit and Vegetables. Journal of Asia-Pacific Entomology, 19, 1191-1195. https://doi.org/10.1016/j.aspen.2016.10.013

[25] SAS Institute Inc. (2012) JMP Statistic Discovery Software version 10.0. Cary, NC.

[26] Liu, Y.B., Yang, X. and Simmons, G. (2016) Efficacy of Nitric Oxide Fumigation for Controlling Codling Moth in Apples. Insects, 7, Article No. 71. https://doi.org/10.3390/insects7040071

[27] Horn, F. and Horn, P. (2004) Fresh Fruit Fumigation with Phosphine as Alternative for Methyl Bromide. Proceedings of 2004 Annual Research Conference on Methyl Bromide Alternatives and Emissions Reductions, Orlando, 31 October-3 November 2004, \#58.

[28] Horn, F., Horn, P. and Sullivan, J. (2005) Current Practice in Fresh Fruit Fumigation with Phosphine in Chile. Proceedings of 2005 Annual Research Conference on Methyl Bromide Alternatives and Emissions Reductions, San Diego, 31 October-3 November 2005, \#61.

[29] Liu, Y.B. (2008) Low Temperature Phosphine Fumigation for Postharvest Control of Western Flower Thrips (Thysanoptera: Thripidae) on Lettuce, Broccoli, Asparagus, and Strawberry. Journal of Economic Entomology, 101, 1786-1791. https://doi.org/10.1603/0022-0493-101.6.1786

[30] Liu, Y.B., Liu, S.S., Simmons, G., Walse, S.S. and Myers, S.W. (2013) Effects of Phosphine Fumigation on Survivorship of Epiphyas postvittana (Lepidoptera: Tortricidae) Eggs. Journal of Economic Entomology, 106, 1613-1618. https://doi.org/10.1603/EC13050

[31] Liu, S.S., Liu, Y.B. and Simmons, G. (2014) Oxygenated Phosphine Fumigation for Control of Epiphyas postvittana (Lepidoptera: Tortricidae) Eggs on Lettuce. Journal of Economic Entomology, 107, 1370-1376. https://doi.org/10.1603/EC13487

[32] Yang, X. and Liu, Y.B. (2019) Nitric Oxide Fumigation for Postharvest Pest Control on Lettuce. Pest Management Sciences, 75, 390-395.

https://doi.org/10.1002/ps.5123

[33] Yang, X. and Liu, Y.B. (2018) Nitric Oxide Fumigation for Control of Spotted Wing Drosophila (Diptera: Drosophilidae) in Strawberries. Journal of Economic Entomology, 111, 1180-1184. https://doi.org/10.1093/jee/toy074

[34] Beaudry, R.M. (1999) Effect of $\mathrm{O}_{2}$ and $\mathrm{CO}_{2}$ Partial Pressure on Selected Phenomena Affecting Fruit and Vegetable Quality. Postharvest Biology and Technology, 15, 293-303. https://doi.org/10.1016/S0925-5214(98)00092-1

[35] Liu, Y.B. (2008) Ultralow Oxygen Treatment for Postharvest Control of Western Flower Thrips, Frankliniella occidentalis (Thysanoptera: Thripidae), on Iceberg Lettuce, II. Effects of Pre-Treatment Storage on Lettuce Quality. Postharvest Biology and Technology, 49, 135-139. https://doi.org/10.1016/j.postharvbio.2008.01.007

[36] Liu, Y.B. (2017) Nitric Oxide Fumigation for Control of Bulb Mites on Flower Bulbs. Journal of Economic Entomology, 110, 2046-2051.

https://doi.org/10.1093/jee/tox187 